\title{
Cytoplasmic Lipid Accumulation Characteristic of the Cribriform Variant of Papillary Thyroid Carcinoma
}

\author{
Nami Takada ${ }^{a}$ Mitsuyoshi Hirokawa ${ }^{b}$ Aki Ito $^{a}$ Ayana Suzuki ${ }^{a}$ \\ Miyoko Higuchi $^{a}$ Seiji Kumab ${ }^{\text {Toshitetsu Hayashi }}{ }^{\text {b }}$ Tsutomu Daa ${ }^{d}$ \\ Akira Miyauchic \\ Departments of a Clinical Laboratory, ${ }^{\mathrm{b}}$ Diagnostic Pathology and Cytology, and ${ }^{\mathrm{C} S u r g e r y}$, Kuma Hospital, Kobe, and \\ ${ }^{\mathrm{d}}$ Department of Diagnostic Pathology, Faculty of Medicine, Oita University, Yufu, Japan
}

\section{Keywords}

Cribriform variant $\cdot$ Papillary thyroid carcinoma $\cdot$ Subnuclear lipid accumulation · Foamy cytoplasm · Adipophilin

\section{Abstract}

Objective: The purpose of this study was to clarify the diagnostic significance of cytoplasmic lipid accumulation (CLIA) in the cribriform variant of papillary thyroid carcinoma (CVPTC). Methods: We performed a histological, immunohistochemical, and cytological examination of 35 CV-PTC cases at the Kuma Hospital. CLIA was defined as bubble-like multivacuolation in cytoplasm with distinct cell border. We also examined 100 conventional PTC (con-PTC) cases as controls. Results: Histological analysis showed the presence of carcinoma cells with CLIA in $60.0 \%$ of CV-PTC and $5.0 \%$ of con-PTC cases. The vacuoles tended to distribute in the subnuclear portion of carcinoma cells showing papillary growth. They were positive for oil red $\mathrm{O}$ staining and adipophilin. The carcinoma cells without the vacuoles showed a subnuclear dotlike expression for adipophilin in CV-PTC cases, but not in the con-PTC cases. Cytological analysis showed CLIA in 17 $(54.8 \%)$ of the 31 CV-PTC cases, but not in the con-PTC cases. Conclusion: This is the first study to report the presence of

\section{KARGER}

E-Mail karger@karger.com www.karger.com/pat

\section{(C) 2017 The Author(s)}

Published by S. Karger AG, Basel

Karger

open access

This article is licensed under the Creative Commons AttributionNonCommercial-NoDerivatives 4.0 International License (CC BYNC-ND) (http://www.karger.com/Services/OpenAccessLicense). Usage and distribution for commercial purposes as well as any distribution of modified material requires written permission. carcinoma cells with CLIA in CV-PTC. The subnuclear dot-like expression of adipophilin may be characteristic of CV-PTC. These findings might be related to degenerative changes occurring in CV-PTC.

(c) 2017 The Author(s)

Published by S. Karger AG, Basel

\section{Introduction}

The cribriform variant of papillary thyroid carcinoma (CV-PTC) is a rare variant of PTC and constitutes $<0.5 \%$ of all PTCs [1]. It usually occurs in young women and is commonly associated with familial adenomatous polyposis (FAP) [2]. However, the sporadic form of CV-PTC without FAP has been reported [3].

The histological and cytological features of CV-PTC have been well documented. Histologically, it is characterised by papillary growth composed of tall columnar cells, a cribriform structure without colloid, solid growth, morules, and peculiar nuclear clearing (PNC) [2-6]. Cytologically, CV-PTC is characterised by hypercellularity, a papillary arrangement composed of tall columnar cells, cribriform pattern, morules, spindle cells, obscure groundglass nuclei, PNC, foamy or haemosiderin-laden histio- 
Table 1. Carcinoma cells with cytoplasmic lipid accumulation in CV-PTC and con-PTC

\begin{tabular}{|c|c|c|c|c|}
\hline & \multicolumn{2}{|l|}{ CV-PTC $(n=35)$} & \multicolumn{2}{|c|}{ Con-PTC $(n=100)$} \\
\hline & CLIA (+) & CLIA $(-)$ & CLIA $(+)$ & CLIA $(-)$ \\
\hline Cases & $21(60.0)^{*}$ & $14(40.0)$ & $5(5.0)^{*}$ & $95(95.0)$ \\
\hline Age, years & $17-49(27.1)$ & $18-39(27.2)$ & $40-77(55.4)$ & $18-80(51.8)$ \\
\hline Male/female & $0 / 21$ & $0 / 14$ & $1 / 4$ & $14 / 81$ \\
\hline $\mathrm{TC}, \mathrm{mg} / \mathrm{dL}$ & $136-293(189.2)$ & $135-255(175.1)$ & $178-254(210.2)$ & $118-325(191.8)$ \\
\hline FAP/non-FAP/NE & $8 / 9 / 4$ & $8 / 4 / 2$ & $0 / 0 / 5$ & $0 / 0 / 95$ \\
\hline Tumour size, mm & $4-71(24.6)$ & $5-46(21.3)$ & $6-37(18.4)$ & $3-45(14.8)$ \\
\hline Microscopic cystic change & $14(66.7)$ & $6(42.9)$ & $4(80.0)^{* *}$ & $15(15.8)^{* *}$ \\
\hline Regional nodal metastasis ${ }^{1}$ & $1(4.8)$ & $1(7.1)$ & $3(60.0)$ & $58(61.1)$ \\
\hline Distant metastasis ${ }^{2}$ & $0(0)$ & $1(7.1)$ & $0(0)$ & $1(1.1)$ \\
\hline
\end{tabular}

Data are $n(\%)$ or range (mean). CV-PTC, cribriform variant of papillary thyroid carcinoma; con-PTC, conventional papillary thyroid carcinoma; CLIA, carcinoma cells with cytoplasmic lipid accumulation; TC, total cholesterol; FAP, familial adenomatous polyposis; NE, non-examined. ${ }^{1}$ At operation. ${ }^{2}$ During follow-up. ${ }^{*} p<$ $0.001,{ }^{* *} p<0.01$

cytes, hyaline materials, and an absence of colloid in the background $[5,7]$. We recently identified carcinoma cells with a foamy cytoplasm containing a lipid component in CV-PTC cases. To the best of our knowledge, these findings have not been observed in CV-PTC. Therefore, this study aimed to clarify the diagnostic significance of carcinoma cells with cytoplasmic lipid accumulation (CC-CLIA).

\section{Materials and Methods}

We reviewed 11,000 PTC cases that were histologically diagnosed at Kuma Hospital from March 2005 to July 2015. Thirty-five of them $(0.3 \%)$ were CV-PTC cases. A histological diagnosis of CV-PTC was made on the basis of the following criteria: (1) papillary growth composed of tall columnar cells, (2) cribriform architecture without colloid, (3) solid and spindle cell areas, (4) morules, and (5) PNC. The diagnoses of all cases were confirmed by findings of nuclear and cytoplasmic expression for $\beta$-catenin ( $\beta$-catenin 1, 1:200; Dako, Carpinteria, CA, USA) and nuclear positivity for ER (6F11, 1:400; Novocastra, Newcastle, UK) on immunohistochemical analysis. All of the patients with CV-PTC were women, and the mean age was 27.1 years (range 17-49). Sixteen cases were associated with FAP, 13 cases were not, and the remaining 6 cases were not examined. Multiple CV-PTC nodules were found in $12(75.0 \%)$ of the 16 FAP cases, but none were found in the 13 non-FAP cases and 6 non-examined cases. The sizes of the nodules ranged from 4 to $71 \mathrm{~mm}$ (mean 23.5). We examined the 35 CV-PTC cases histologically, histochemically, and immunohistochemically. CLIA was defined as bubble-like multivacuolation in cytoplasm with distinct cell border. Additionally, we focused on carcinoma cells with septate cytoplasmic vacuoles (CC-SCV) that were similar to CC-CLIA. In cases with multiple nodules, we examined the largest nodule.
Fine-needle aspiration cytology (FNAC) specimens were available for 31 of the $35 \mathrm{CV}$-PTC cases. FNAC was performed preoperatively using a 22-G needle under ultrasound guidance. The preparations were smeared using the conventional method, fixed with Cytorop (Alfresa Pharma, Osaka, Japan), which is a cytological fixative, and stained with Papanicolaou stain. In addition, we observed CC-CLIA and CC-SCV in the cytological preparations.

In this study, we also included 100 consecutive conventional PTC (con-PTC) patients who underwent resection at Kuma Hospital from January to February 2015 as control cases. Preoperative cytological specimens were available for 86 of these patients.

To identify the lipid accumulation in carcinoma cells, we performed oil red $\mathrm{O}$ staining [6] using 5- $\mu \mathrm{m}$ frozen tissue sections from formalin-fixed specimens in $1 \mathrm{CV}$-PTC and 3 con-PTC cases. Immunohistochemical staining for adipophilin (AP125; Acris Antibodies $\mathrm{GmbH}$, Hiddenhausen, Germany) was performed for 19 CV-PTC and 9 con-PTC cases. The sections were deparaffinised in xylene and rehydrated in a graded ethanol series. Endogenous peroxidase activity was abolished by incubation with $3 \%$ hydrogen peroxide for $20 \mathrm{~min}$ at room temperature. The slides were autoclaved in citrate buffer ( $\mathrm{pH}$ 6.0) at $121^{\circ} \mathrm{C}$ for $15 \mathrm{~min}$ and stained using the labelled streptavidin-biotin peroxidase complex system. Statistical significance of the data was analysed using statistical software Stat Flex v.6 (Artech Co., Ltd, Osaka, Japan). A value of $p<0.05$ in the Fisher probability test was considered statistically significant.

\section{Results}

Histological analysis showed the presence of CC-CLIA in $60.0 \%$ of CV-PTC and $5.0 \%$ of con-PTC cases (Table 1 ). The incidence of CC-CLIA in CV-PTC cases was significantly higher than that in con-PTC cases $(p<0.001)$. Fur- 
Table 2. Differences between CC-CLIA and CC-SCV

\begin{tabular}{lll}
\hline & CC-CLIA & CC-SCV \\
\hline $\begin{array}{ll}\text { Occurrence } \\
\text { Distribution }\end{array}$ & CV-PTC > con-PTC & Con-PTC \\
Location & Focal & Focal \\
Cell shape & Papillae with cystic change & Papillae with cystic change \\
Cytoplasm & Tall columnar & Hobnail \\
Vacuoles & Pale, foamy & Dense, multivacuolated \\
\multicolumn{1}{l}{$\begin{array}{l}\text { Location } \\
\text { Border }\end{array}$} & Subnuclear (basal) & \\
Adipid (oil red O stain) & Obscure & Supranuclear (apical) \\
& Positive & Clear \\
& Positive & Positive \\
\end{tabular}

CC-CLIA, carcinoma cells with cytoplasmic lipid accumulation; CC-SCV, carcinoma cells with septate cytoplasmic vacuoles; CV-PTC, cribriform variant of papillary thyroid carcinoma; con-PTC, conventional papillary thyroid carcinoma.
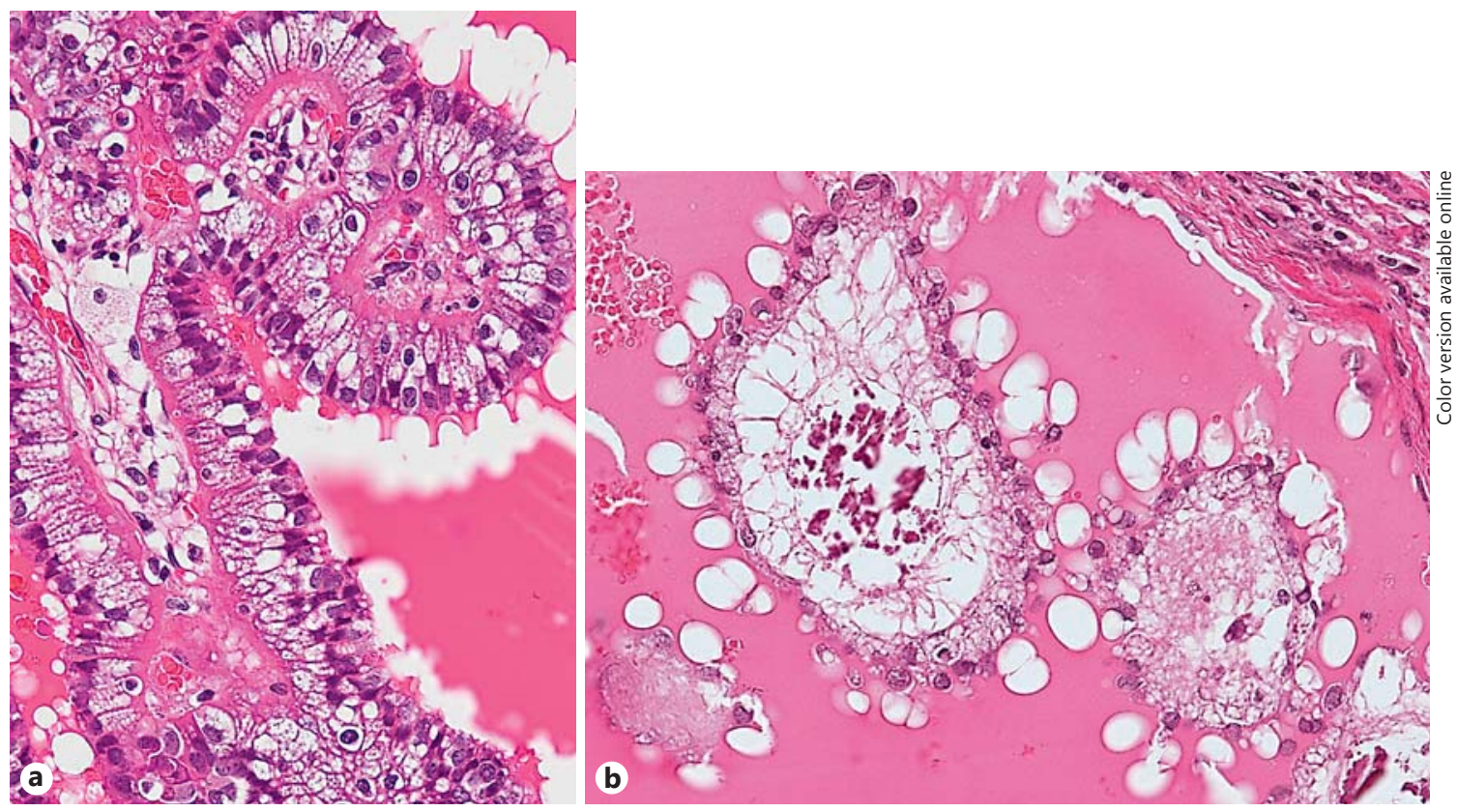

Fig. 1. Histology of the cribriform variant of papillary thyroid carcinoma (a) and conventional papillary thyroid carcinoma (b). a The carcinoma cells are tall, columnar cells, and intracytoplasmic vacuoles are located in the subnuclear portion. $\mathbf{b}$ The carcinoma cells with intracytoplasmic vacuoles located in the subnuclear portion are not tall.

thermore, the occurrence of CC-CLIA was not related to the age, total cholesterol level, association with FAP, tumour size, regional nodal metastasis at operation, or distant metastasis during follow-up (Table 1). CC-CLIA was a minor component of the tumour and mainly located at the papillae protruding into the cystic spaces (Table 2). Microscopic cystic changes were noted in $66.7 \%$ of CV-PTC cases with and $42.9 \%$ of those without CC-CLIA, respectively. Con-PTC cases with CC-CLIA (80.0\%) showed these changes more frequently than those without CCCLIA $(15.8 \% ; p<0.01)$. In the CV-PTC cases, the vacuoles tended to distribute in the subnuclear portion of carcinoma cells that were usually tall columnar cells (Fig. 1a), and the margin of the vacuoles was ill defined. Solid or 


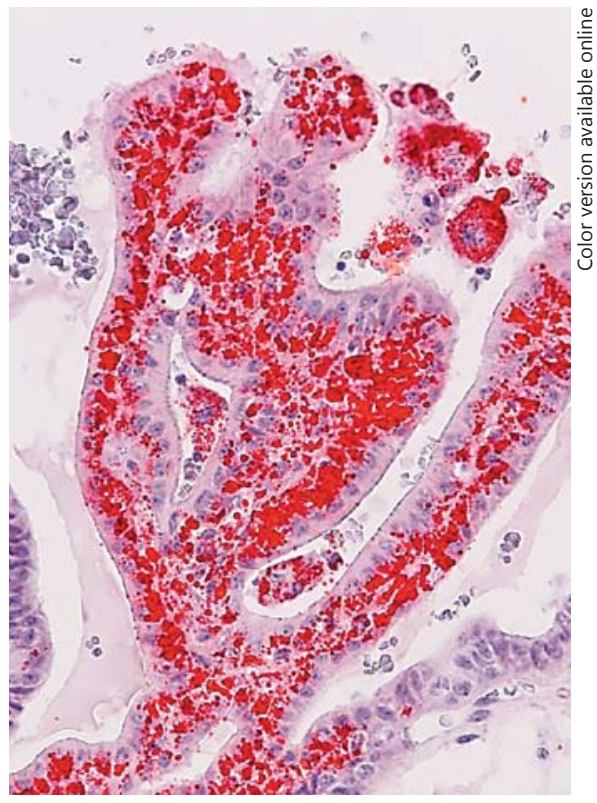

Fig. 2. Oil red $\mathrm{O}$ staining in the cribriform variant of papillary thyroid carcinoma. The vacuoles are strongly positive for oil red $\mathrm{O}$ stain.

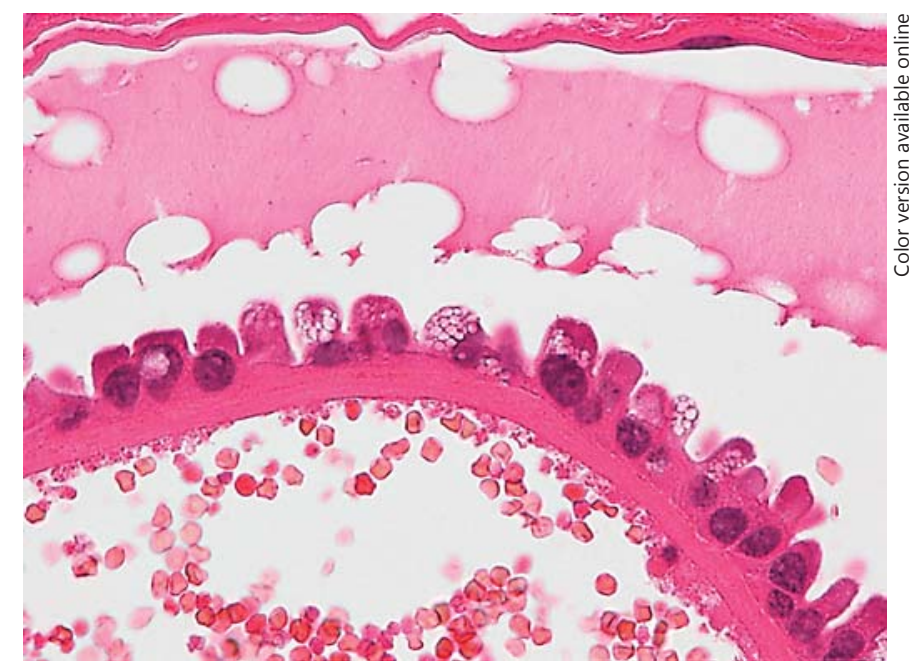

Fig. 3. Histology of conventional papillary thyroid carcinoma. The vacuoles are present at the apical portion of the carcinoma cells with a hobnail appearance, and dense cytoplasm is seen between the vacuoles.
Fig. 4. Immunohistochemistry using the antibody for adipophilin in the cribriform variant of papillary thyroid carcinoma. a The intracytoplasmic vacuoles are positive for adipophilin. b Non-vacuolated carcinoma cells show a dot-like expression in the basilar portion.

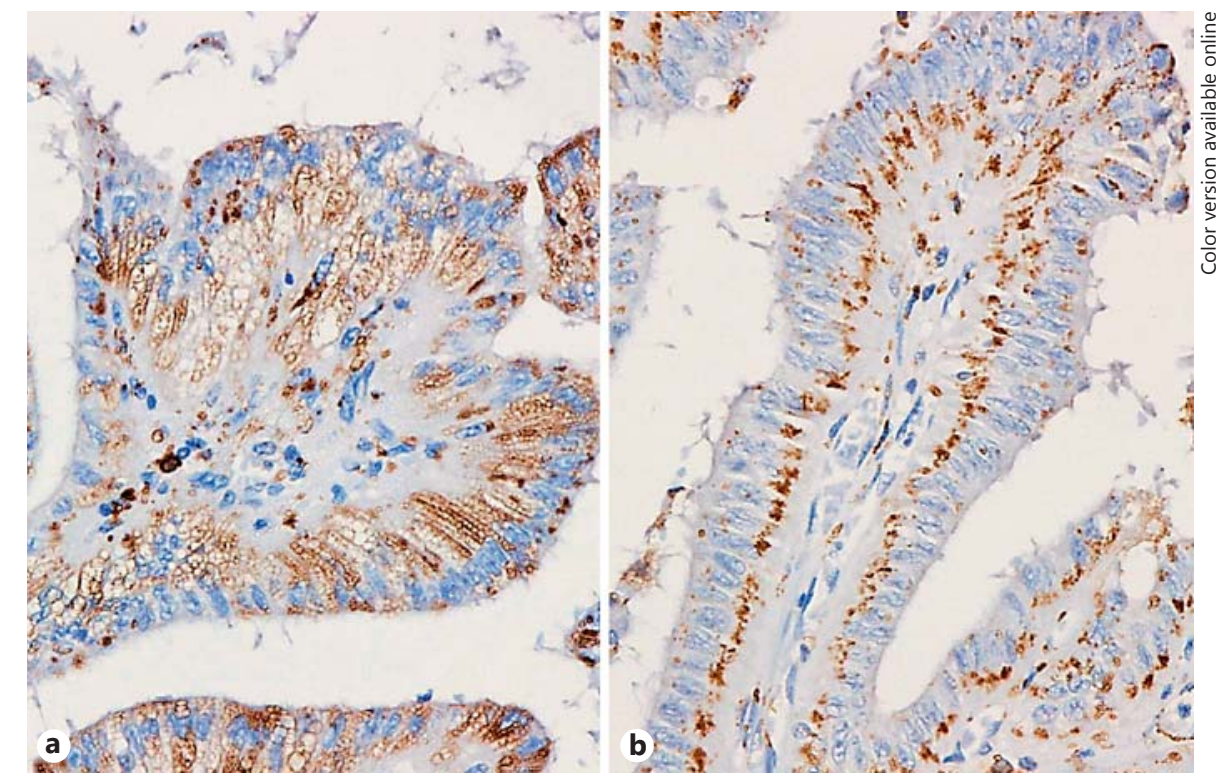

cribriform areas occasionally exhibited CC-CLIA. The vacuoles seen in the con-PTC cases were morphologically similar, but the carcinoma cells with vacuoles were not tall (Fig. 1b). In areas representing abundant CC-CLIA, foamy histiocytes were observed in the stroma. Oil red $\mathrm{O}$ staining demonstrated in 1 case that the vacuoles of CC-
CLIA and foamy histiocytes in the stroma were intensively positive (Fig. 2). The aggregation of foamy histiocytes in the stroma was also observed in con-PTC cases.

CC-SCV was observed in $7.0 \%$ of con-PTC cases, but in none of the CV-PTC cases. SCV were present in the carcinoma cells located in the papillae that protruded into 


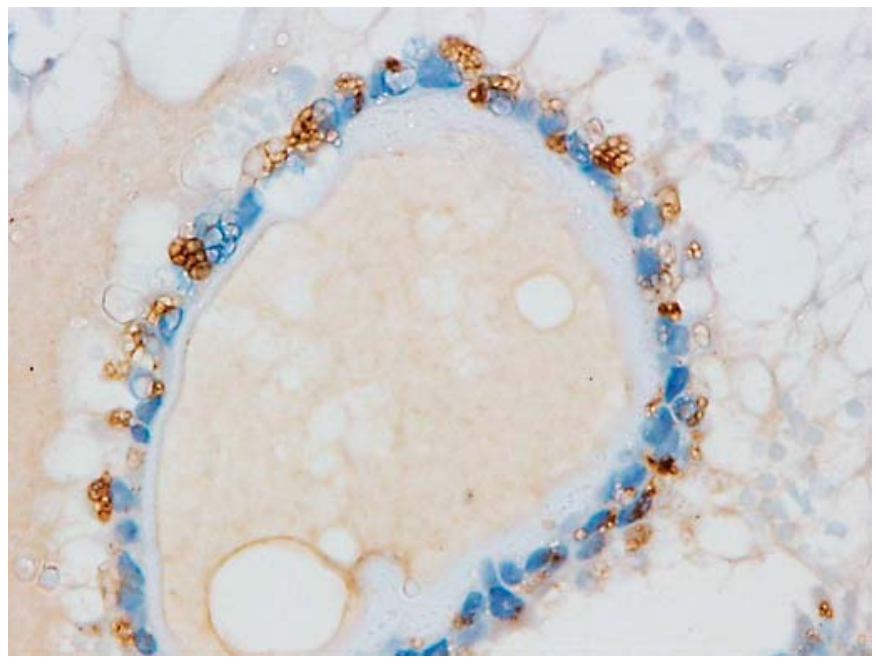

Fig. 5. Immunohistochemistry using the antibody for adipophilin in conventional papillary thyroid carcinoma. Septate cytoplasmic vacuoles are positive for adipophilin.

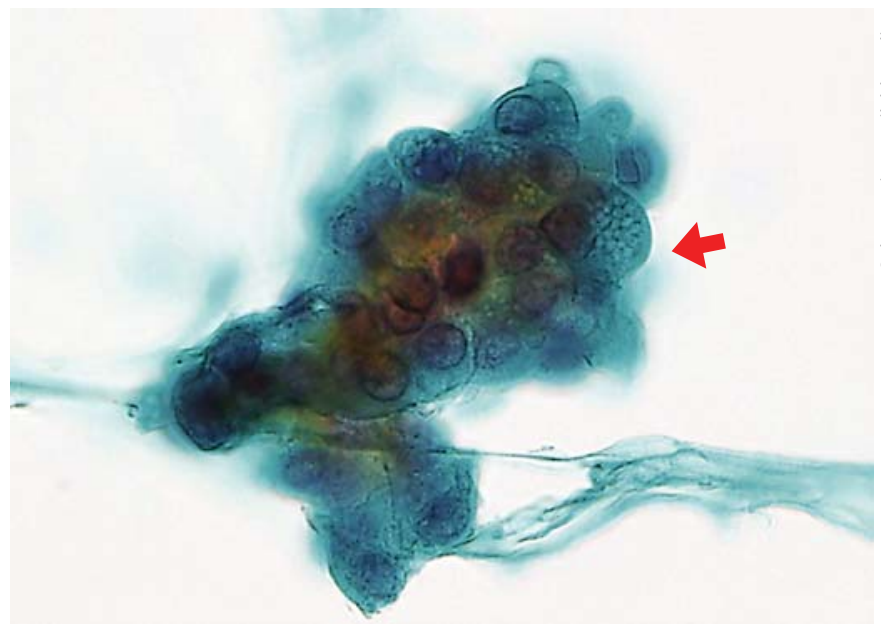

Fig. 7. Cytology of conventional papillary thyroid carcinoma. Septate cytoplasmic vacuoles are present in the dense metaplastic cytoplasm (arrow).

the cystic spaces, similar to CLIA (Table 2). CC-SCV showed a hobnail appearance, and the vacuoles were present in the apical portion (Fig. 3). A dense cytoplasm was present between the vacuoles, and the vacuoles were positive for oil red $\mathrm{O}$ staining, but the reaction was weaker than that seen with CLIA.

Immunohistochemically, the intracytoplasmic vacuoles of CC-CLIA and foamy histiocytes in the stroma were positive for adipophilin (Fig. 4a). The staining pat-

Cytoplasmic Lipid Accumulation in CV-PTC

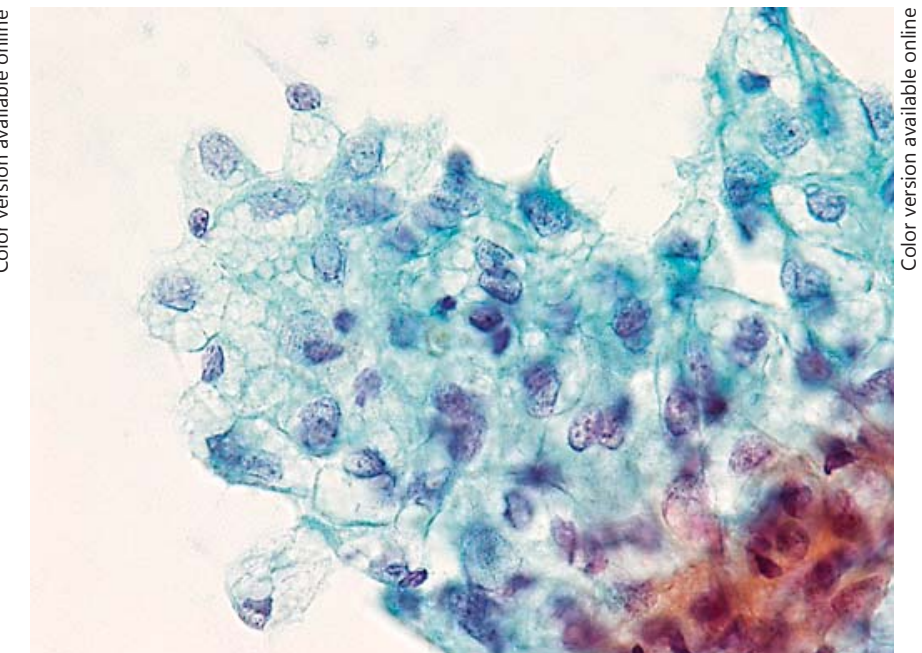

Fig. 6. Cytology of the cribriform variant of papillary thyroid carcinoma. The cytoplasm is abundant, clear, and vacuolated.

tern was similar in CV-PTC and con-PTC cases. Nonvacuolated carcinoma cells in CV-PTC cases showed a dot-like expression in the basilar portion (Fig. 4b), but this finding was minimal in the con-PTC cases. SCV in the con-PTC cases were positive for adipophilin, but the expression was not strong (Fig. 5).

Of the $31 \mathrm{CV}-\mathrm{PTC}$ patients who underwent FNAC, 17 (54.8\%) patients showed CC-CLIA; of these, 11 patients showed CC-CLIA in the histological analysis as well. No con-PTC cases showed CC-CLIA $(p<0.001)$. CC-CLIA appeared as 2-dimensional cell clusters with distinct cell borders (Fig. 6). The cytoplasm was abundant, clear, and vacuolated. The vacuoles were present throughout the cytoplasm, and the border was obscure. SCV were observed in 7 (8.1\%) of the 86 con-PTC cases and appeared as 3 -dimensional clusters in some carcinoma cells (Fig. 7). The vacuoles appeared in a dense metaplastic cytoplasm and showed distinct borders. No CC-CLIA were observed in the con-PTC cases.

\section{Discussion}

The histologic features of CV-PTC are well documented and include papillary growth composed of tall columnar cells, a cribriform structure without colloid, solid growth, morules, and PNC [2-5]. In this study, we identified carcinoma cells with a pale and vacuolated cytoplasm in CV-PTC cases. The vacuoles tended to distribute in a 
subnuclear portion of tall carcinoma cells protruding into cystic spaces. To the best of our knowledge, these findings have not been reported in CV-PTC thus far. As the cells were positive for oil red $\mathrm{O}$ staining and adipophilin, their abovementioned appearance may be due to lipid accumulation [8]. Therefore, we termed these carcinoma cells with CLIA (CC-CLIA). Although CC-CLIA were a minor component of CV-PTC, they were observed in $60 \%$ of CV-PTC cases. The incidence of CC-CLIA in CV-PTC cases was significantly higher than that in the con-PTC cases. Therefore, CC-CLIA should be recognised as a characteristic feature of CV-PTC.

Some neoplasms with a foamy appearance, excluding adipocyte-derived carcinomas, have been described in the literature. Noro et al. [9] reported a case of hepatocellular carcinoma with a foamy histiocyte-like appearance. Pancreatic ductal adenocarcinoma [10] and prostatic adenocarcinoma [11] can also appear with a foamy cytoplasm. However, the presence of lipid accumulation in carcinoma cells has not been demonstrated thus far. Several cases of mesothelioma with a foamy cytoplasm have been reported [12-17], and intracytoplasmic lipid accumulation was reported in 2 cases [12, 14]. In addition, in a case of papillary mesothelioma of the peritoneum [14], cytoplasmic vacuoles containing lipid droplets were located in the basal portion of tumour cells that showed papillary growth. These findings are similar to the vacuoles seen in CC-CLIA in the current study. As both PTC and mesothelioma are not adipocyte-derived tumours, the intracytoplasmic fatty accumulation could be a degenerative change. Papillary growth may be involved in the pathogenesis.

Aggregation of foamy histiocytes in the stroma of papillae was occasionally seen in con-PTC cases [18]. In our study, this finding was observed in both con-PTC and $\mathrm{CV}$-PTC cases. Therefore, we believe such aggregation is not specific to CV-PTC.

SCV represent one of the characteristic cytologic findings of PTC. They are small, uniform, and well-defined vacuoles, with defined strands of cytoplasm-separating vacuoles [19]. In our study, SCV were apparently similar to foamy cytoplasm in CV-PTC. The findings also tended to be observed in carcinoma cells showing papillary growth and presented with lipid accumulation. Similar to CLIA, SCV seemed to be related to degenerative changes [19], but the location of the vacuoles was different. The vacuoles in CV-PTC cases appeared in the subnuclear portion, whereas SCV were present in the apical portion of the hobnail carcinoma cells. These findings may be pathophysiologically similar, but their diagnostic significance is different.

Interestingly, in immunohistochemical analysis, even carcinoma cells without intracytoplasmic vacuoles showed adipophilin expression in a dot-like pattern in the basilar part of the carcinoma cells. Subnuclear staining for adipophilin was also demonstrated in a case of gastric hyperplastic polyp with dysplasia [20], and 2 possible mechanisms for lipid accumulation were considered, namely absorption and production. Based on our observations discussed above, we consider lipid production as the underlying mechanism for CLIA. Therefore, a dot-like pattern could represent the initial and minimal degeneration of carcinoma cells in CV-PTC or suggest the easy degeneration of carcinoma cells. As these findings were rarely observed in con-PTC cases, they might indicate the presence of CV-PTC. To confirm this finding, further studies using a larger sample size should be performed.

In cytological specimens, CC-CLIA appeared as 2-dimensional cell clusters with distinct cell borders. The cytoplasm was abundant, clear, and vacuolated. The vacuoles were present throughout the cytoplasm, and the border was obscure. CC-CLIA were observed in $54.8 \%$ of CV-PTC cases, but not in the con-PTC cases. Their incidence was not low compared with other characteristic findings of CV-PTC, such as cribriform structure (63.2\%), morules (52.6\%), and PNC (36.8\%) [5]. Therefore, the presence of CLIA could be a useful indicator of CV-PTC on FNAC. However, the intracytoplasmic vacuoles can be observed in the other tumours in thyroid FNAC. It is important to note that the differential diagnoses of CCCLIA include metastatic renal cell carcinoma [21], follicular carcinoma [22], and papillary carcinoma [23].

In conclusion, we showed that CLIA is a characteristic feature of CV-PTC. The vacuoles tended to distribute in the subnuclear portion of carcinoma cells showing papillary growth and were positive for oil red $\mathrm{O}$ staining and adipophilin. A subnuclear dot-like expression for adipophilin was characteristic of carcinoma cells without intracytoplasmic vacuoles in the CV-PTC cases. These findings might indicate the presence of CV-PTC and could be related to degenerative changes in CV-PTC.

\section{Disclosure Statement}

None of the authors have any potential conflicts of interest associated with this research.
Takada/Hirokawa/Ito/Suzuki/Higuchi/ Kuma/Hayashi/Daa/Miyauchi 


\section{References}

1 Sak SD: Variants of papillary thyroid carcinoma: multiple faces of a familiar tumor. Turk Patoloji Derg 2015;31:34-47.

2 Harach HR, Williams GT, Williams ED: Familial adenomatous polyposis associated thyroid carcinoma: a distinct type of follicular cell neoplasm. Histopathology 1994;25:549561.

3 Cameselle-Teijeiro J, Chan JK: Cribriformmorular variant of papillary carcinoma: a distinctive variant representing the sporadic counterpart of familial adenomatous polyposis-associated thyroid carcinoma? Mod Pathol 1999;12:400-411.

4 Tomoda C, Miyauchi A, Uruno T, Takamura Y, Ito Y, Miya A, Kobayashi K, Matsuzuka F, Kuma S, Kuma K, Kakudo K: Cribriformmorular variant of papillary thyroid carcinoma: clue to early detection of familial adenomatous polyposis-associated colon cancer. World J Surg 2004;28:886-889.

5 Hirokawa M, Maekawa M, Kuma S, Miyauchi A: Cribriform-morular variant of papillary thyroid carcinoma - cytological and immunocytochemical findings of 18 cases. Diagn Cytopathol 2000;38:890-896.

6 Kuma S, Hirokawa M, Xu B, Miyauchi A, Kukudo K, Sano T: Cribriform-morular variant of papillary thyroid carcinoma: report of a case showing morules with peculiar nuclear clearing. Acta Cytol 2004;48:431-436.

7 Hirokawa M, Kuma S, Miyauchi A, Qian ZR, Nakasono M, Sano T, Kakudo K: Morules in cribriform-morular variant of papillary thyroid carcinoma: immunohistochemical characteristics and distinction from squamous metaplasia. APMIS 2004;112:275-282.
8 Bobulescu IA, Lotan Y, Zhang J, Rosenthal TR, Rogers JT, Adams-Huet B, Sakhaee K, Moe OW: Triglycerides in the human kidney cortex: relationship with body size. PLoS One 2014;29:e101285.

9 Noro T, Gotohda N, Kojima M, Konishi M, Nakaghori T, Takahashi S, Hasebe T, Kinoshita T: Hepatocellular carcinoma with foamy histiocyte-like appearance: a deceptively clear cell carcinoma appearing variant. Case Rep Gastroenterol 2010;4:286-292.

10 Adsay V, Logani S, Sarkar F, Crissman J, Vaitkevicius V: Foamy gland pattern of pancreatic ductal adenocarcinoma: a deceptively benign-appearing variant. Am J Surg Pathol 2000;24:493-504.

11 Warrick JI, Humphrey PA: Foamy gland carcinoma of the prostate in needle biopsy: incidence, Gleason grade, and comparative $\alpha$ methylacyl-CoA racemase versus ERG expression. Am J Surg Pathol 2000;37:17091714.

12 Cavazza A, Pasquinelli G, Agostini L, Leslie KO, Colby TV: Foamy cell mesothelioma. Histopathology 2002;41:369-371.

13 Ordonez NG: The use of immunohistochemistry in the diagnosis of composite and collision tumors: exemplified by pleural mesothelioma and carcinoid tumor of the lung. Appl Immunohistochem Mol Morphol 2012;20: 421-426.

14 Stolnicu S, Quiñonez E, Boros M, Molnar C, Dulcey I, Nogales FF: Case report: papillary mesothelioma of the peritoneum with foamy cell lining. Diagn Pathol 2013;8:162.

15 Kitazawa M, Kaneko H, Toshima M, Ishikawa $\mathrm{H}$, Kobayashi H, Sekiya M: Malignant peritoneal mesothelioma with massive foamy cells: codfish roe-like mesothelioma. Acta Pathol Jpn 1984;34:687-692.
16 Komorowski RA, Bobert DH: Peritoneal mesothelioma presenting as an adnexal mass. South Med J 1975;68:83-85.

17 Mikuz G, Höpfel-Kreiner I: Papillary mesothelioma of the tunica vaginalis propria testis: case report and ultrastructural study. Virchows Arch A Pathol Anat Histol 1982;396: 231-238.

18 Wartofsky L, van Nostrand D: Thyroid Cancer: A Comprehensive Guide to Clinical Management, ed 3 revised. New York, Springer, 2016, p 382.

19 Hirokawa M, Kanahara T, Habara T, Fujimura N, Horiguchi H, Wakatsuki S, Sano T: Dilated rough endoplasmic reticulum corresponding to septate cytoplasmic vacuoles in papillary thyroid carcinoma. Diagn Cytopathol 2000;23:351-353.

20 Ueyama H, Matsumoto K, Nagahara A, Gushima R, Hayashi T, Yao T, Watanabe S: A white opaque substance-positive gastric hyperplastic polyp with dysplasia. World J Gastroenterol 2013;19:4262-4266.

21 Lew M, Foo WC, Roh MH: Diagnosis of metastatic renal cell carcinoma on fine-needle aspiration cytology. Arch Pathol Lab Med 2014; 138:1278-1285.

22 Ng WK, Tang V, Poon CS: Fine needle aspiration cytology of follicular carcinoma with clear cell change: a case report. Acta Cytol 2002;46:757-761.

23 Yang GC, Fried K, Scognamiglio T: Cytological features of clear cell thyroid tumors, including a papillary thyroid carcinoma with prominent hobnail features. Diagn Cytopathol 2013;41:757-761. 